\title{
Effects of Tooth Loss
}

\section{and the Apolipoprotein $E \varepsilon 4$ Allele on Mild Memory Impairment in the Fujiwara-kyo Study of Japan: A Nested Case-Control Study}

\author{
Nozomi Okamoto ${ }^{\mathrm{a}, *}$, Masayuki Morikawa ${ }^{\mathrm{b}, \mathrm{c}}$, Nobuko Amano ${ }^{\mathrm{d}}$, Motokazu Yanagi ${ }^{\mathrm{e}}$, \\ Shin Takasawa ${ }^{\mathrm{f}}$ and Norio Kurumatani ${ }^{\mathrm{a}}$ \\ ${ }^{a}$ Department of Community Health and Epidemiology, Nara Medical University, Nara, Japan \\ ${ }^{\mathrm{b}}$ Mie Prefectural Mental Medical Center, Mie, Japan \\ ${ }^{\mathrm{c}}$ Department of Psychiatry, Nara Medical University, Nara, Japan \\ ${ }^{\mathrm{d}}$ Konan Women's University, Hyogo, Japan \\ ${ }^{\mathrm{e}}$ Department of Food and Nutrition, Tezukayama University, Nara, Japan \\ ${ }^{\mathrm{f}}$ Department of Biochemistry, Nara Medical University, Nara, Japan
}

Accepted 23 August 2016

\begin{abstract}
.
Background: Several studies have suggested that periodontal disease can exacerbate the pro-inflammatory status of the brain. Tooth loss is one of the alternative evaluation indices of periodontal disease. There are few data on the relationship between tooth loss and memory impairment, depending on the apolipoprotein $\mathrm{E}(A P O E) \varepsilon 4$ genotype.

Objective: To determine if tooth loss is associated with mild memory impairment (MMI) and if this association is modified by the presence of the $A P O E \varepsilon 4$ allele.

Methods: A nested case-control study was conducted from 2007 to 2012 in Japan. Five hundred and thirty-seven Japanese subjects aged 65 years and over who were cognitively intact at baseline were analyzed. MMI at follow-up was evaluated.

Results: The median number of teeth at baseline was significantly lower in MMI participants $(n=179)$ than in controls $(n=358)$ (MMI: median 21.0, interquartile range 10.0-25.0 versus controls: 24.0, 14.0-27.0). After adjustment for demographics, vascular risk factors, and $A P O E \varepsilon 4$ allele, the multivariate adjusted odds ratio (OR) of $\leq 8$ teeth was 1.97 (95\% confidence interval [CI], 1.13-3.44) compared to 25-32 teeth. Participants with both the presence of at least 1 APOE $\varepsilon 4$ allele and $\leq 8$ teeth had a higher risk of MMI compared with those with neither (OR, 2.82; 95\% CI, 1.15-6.91). Those with either risk factor alone did not have a higher risk of MMI.

Conclusions: A lower number of teeth is related to risk of MMI. This may be primarily true for those individuals with an $A P O E \varepsilon 4$ allele.
\end{abstract}

Keywords: APOE $\varepsilon 4$ allele, community-based, memory decline, nested case-control study, tooth loss

\section{INTRODUCTION}

*Correspondence to: Nozomi Okamoto, DDS, PhD, Shijo-cho 840, Kashihara city, Nara 6348521, Japan. Tel.: +81 744298841 ; Fax: +81 744 0673; E-mail: onozomi@naramed-u.ac.jp.
The prevalence of Alzheimer's disease (AD) and dementia is on the increase all over the world. The conversion rate from mild cognitive impairment 
(MCI) to dementia is reportedly $50 \%$ within 5 years $[1,2]$. To reduce the number of patients developing dementia, it is crucial to identify modifiable risk factors of MCI for its prevention. The Nakayama study group [3] reported a simple diagnostic method for MCI using the Mini-Mental State Examination (MMSE) [4], in which the existence of mild memory impairment (MMI) is determined using a threeword delayed recall test (Recall; a subtest of the MMSE). This relatively short examination is suitable for community-based epidemiological surveys. The conversion rate from MMI to illness with dementia is higher than that from cognitively intact individuals, suggesting that MMI is comparable to MCI [3].

In the present study, we focused on periodontal disease as a candidate modifiable risk factor of MMI. Periodontal disease is a chronic inflammatory disease caused mainly by Gram-negative anaerobic bacteria. Locally, resorption of the alveolar bone supporting the teeth results in tooth loss. In that process, there is a possibility that periodontal diseasederived pro-inflammatory molecules, bacteria, and bacterial products increase the risk of developing an inflammatory state in the central nervous system [5]. Previously, some studies reported significant relationships between periodontal infection and lower Digit Symbol test scores in the Wechsler Adult Intelligence Scale [6], and between few teeth at midlife and an increased risk of $\mathrm{AD}$ and dementia [7, 8]. In our 5-year prospective cohort study, we reported that the risk of MMI was increased by 2.4 -fold in edentulous individuals relative to those with multiple teeth [9]. Conversely, one study found no significant correlation between tooth loss and cognitive function due to the high impact of socioeconomic status [10].

The apolipoprotein $\mathrm{E}(A P O E) \varepsilon 4$ allele (rs429358) promotes amyloid aggregation and deposition in the brain, and increases risk for AD [11]. No study has evaluated the correlations between periodontal disease, the $A P O E \varepsilon 4$ allele, and cognitive function, except for the reports from Stein et al. [12-14] and Kamer et al. [15]. However, none of these studies had large sample sizes nor evaluated East Asian individuals. In the present study, the number of remaining teeth and the depth of periodontal pockets were recorded to evaluate the long-term burden of periodontal disease and inflammation of the gingiva at the time of evaluation, respectively. We hypothesized that tooth loss might contribute to MMI. The purpose of this study was to investigate the combined effects of tooth loss and the APOE $\varepsilon 4$ allele on MMI.

\section{METHODS}

\section{Database}

This study was approved by Ethics Review Board of Nara Medical University and Nara Medical University Human Genome and Gene Analysis Research Ethics Committee. We conducted a nested casecontrol study using longitudinal data collected in the Fujiwara-kyo study [16, 17], which started in 2007 and is an ongoing prospective cohort study of volunteer men and women who, at baseline, were independent elderly residents of Nara Prefecture, Japan, aged $\geq 65$ years and able to walk unassisted. In 2007, 4206 people participated in the baseline health assessment. A follow-up assessment for cognitive function was conducted in 2012. Written informed consent was obtained from each subject prior to participation in the baseline and follow-up examinations.

\section{Selection of cases and controls}

Our study population included subjects who were cognitively intact at the baseline survey and had blood samples available for genotyping. Of the 4,206 participants, 3,696 were diagnosed as cognitively intact at baseline. Of these, 2,486 subjects participated in the follow-up assessment (159 died, 42 moved away, 15 were admitted to an institution, 260 were hospitalized or undergoing treatment, and 734 were non-responders). Among the 2,486 participants, 241 subjects who were determined to have MMI at followup were assessed first, and then suitable controls who were judged to be cognitively intact at followup were identified, using frequency matching on age (within 1 year) and sex. For each case, two controls were selected. MMI subjects with no useable blood samples $(n=20)$, who did not wish to undergo gene analysis $(n=31)$, or with no corresponding controls $(n=11)$ were excluded. In the present study, 179 cases and 358 controls were included.

\section{Evaluation of cognitive function}

Being cognitively intact was defined as: (1) no impairment of the activities of daily living (ADL); (2) normal general cognitive function, score $\geq 24$, assessed by the MMSE (score range: 0-30) [18]; and (3) absence of objective memory impairment, score $\geq 2$, assessed by the Recall test (score range: $0-3$ ) in the MMSE, according to the Nakayama study. The MMSE was carried out by clinical psychologists or 
graduate students who majored in psychology. The majority of normal aging individuals should be able to recall 2 or 3 words after a brief delay [19]. Each participant completed a self-administered questionnaire assessing the presence or absence of a disability with the basic ADL (eating, dressing, bathing, and toileting) and the instrumental ADL (using public transportation, shopping for daily necessities, paying bills, and handling one's own banking). When a participant answered "absence of disability" to all of these questions, they were considered as having no impairment of the ADL.

MMI was defined as: (1) no impairment of the ADL; (2) normal general cognitive function, as determined using the MMSE, score $\geq 24$; (3) presence of objective memory impairment, assessed by the Recall test, score $\leq 1$; and (4) absence of depression. The presence or absence of depression was evaluated using the Geriatric Depression Scale short version (GDS) (score range, 0-15; cut-off score, 5/6) [20]. The GDS was also included in the self-administered questionnaire. A GDS score $\geq 6$ indicates the presence of depression symptoms. For a GDS score $\geq 6$, there is a possibility of pseudo-MMI due to depression; therefore, subjects with MMSE $\geq 24$, Recall $\leq 1$, and GDS $\geq 6$ were excluded from the MMI criteria.

We identified the absence or presence of dementia and depression operationally using the MMSE and GDS screening tests, because of the need to shorten the time required for the assessments in such a large-scale community-based survey. The prevalence of MCI defined by Petersen et al. ranges from 3\% to $19 \%$ in community-based epidemiological studies [2]. The prevalence of MMI in our study at baseline (2.9\%: 121/4206) [21] was similar to the prevalence of Japanese community-based MCI [22], 4.9\%, identified using the criteria of Petersen et al. Therefore, the MMI subjects in this study are considered to be approximate to individuals with MCI.

\section{APOE genotypes}

Buffy coats were prepared from whole blood collected at the follow-up survey in 2012. DNA was purified from buffy coats using a QIA symphony DSP DNA Midi Kit (QIAGEN, Hilden, Germany) and stored at $-80^{\circ} \mathrm{C}$. Using TaqMan ${ }^{\circledR}$ SNP Assays (Life Technologies, Carlsbad, CA), single nucleotide polymorphism genotyping of the APOE $\varepsilon 4$ allele (rs429358) was conducted. Individuals with at least one $\varepsilon 4$ allele were determined as APOE $\varepsilon 4$ allelepositive carriers.

\section{Dental examinations}

Dental examinations were carried out by two dentists calibrated as to the techniques using the single observer method, in a sitting position under artificial lighting [9]. The remaining teeth were defined as healthy, carious, or treated (including crowned, inlay, and abutment teeth for bridge work), inclusive of completely erupted third molars. The Community Periodontal Index (CPI) code of the World Health Organization (WHO) [23] was recorded to evaluate the depth of the periodontal pockets. The mouth was divided into 6 sextants: anterior and right and left posterior of the maxillomandibular; a sextant was examined only if there were $\geq 2$ teeth present. The prescribed 10 representative teeth in the 6 sextants were examined at 4 sites on every tooth using a WHO probe. One of 5 code levels (code 0 , healthy; code 1 , gingival bleeding after probing; code 2 , calculus present in the periodontal pocket; code 3 , periodontal pocket 4-5 mm deep; and code 4, periodontal pocket at least $6 \mathrm{~mm}$ deep), or an ineligible sextant (sextant having 1 or zero remaining teeth) was assigned to each sextant. The highest code level identified was regarded as the maximum CPI code for the individual.

\section{Other covariates at baseline}

Vascular risk factors are predictors of cognitive impairment [24-26]. Each participant underwent an interview to record smoking habit, history of cerebrovascular disease, myocardial infarction, hypertension, diabetes mellitus, or dyslipidemia, and current medication. After sitting quietly for $>5 \mathrm{~min}$, blood pressure was determined twice at an interval of $30 \mathrm{~s}$ using an automatic blood-pressure manometer (ES-P2100; TERUMO Co., Tokyo, Japan). The average of 2 measurements was used in the analyses. Blood samples were collected from an antecubital vein after an overnight fast. Cerebrovascular disease and myocardial infarction were determined by medical history and current medication. Hypertension was defined according to the following Japanese Society of Hypertension criteria [27]: medical history, current use of antihypertensive medicine, and/or systolic/diastolic blood pressure $\geq 140 / 90 \mathrm{mmHg}$. Diabetes mellitus was defined by medical history, current antidiabetic medication, and/or by one of the following biochemical test results according to the guidelines of the Japan Diabetes Society [28]: fasting plasma glucose level $\geq 126 \mathrm{mg} / \mathrm{dL}$ or HbA1c level (NGSP) $\geq 6.5 \%$. Dyslipidemia was 
defined by medical history, current lipid-lowering medications, and/or by one of the following biochemical test results according to the Japan Atherosclerosis Society guidelines [29]: triglycerides $\geq 150 \mathrm{mg} / \mathrm{dL}$, low-density lipoprotein cholesterol $\geq 140 \mathrm{mg} / \mathrm{dL}$, or high-density lipoprotein cholesterol $<40 \mathrm{mg} / \mathrm{dL}$.

\section{Statistical analysis}

Statistical analysis was performed using SPSS (IBM, Armonk, NY) version 17.0. Two-tailed $p$ values were calculated in all analyses. The alpha level of significance was set at 0.05 . Descriptive analyses are presented as proportions for categorical data and as medians (interquartile range, IQR) for continuous data. Baseline characteristics were compared between the participants with MMI and controls using the chi-square or Mann-Whitney test. Casecontrol analyses used a logistic regression. MMI at follow-up was used as a dependent variable. We divided the subjects into 4 tooth categories by 8 teeth: groups with 0-8, 9-16, 17-24, and 25-32 teeth. Tooth category at baseline, the number of remaining teeth at baseline, and CPI code (code 4 versus code $0,1,2$, or 3 ) at baseline were used as independent variables.
Dental variables were added separately to each model. Multivariate-adjusted odds ratios (ORs) and 95\% confidence intervals (CIs) of each dental variable were calculated controlling for baseline age, sex, educational background ( $\leq$ junior high school versus $\geq$ high school), baseline MMSE-total scores, baseline Recall ( 2 score versus 3 score), and baseline GDS ( $\geq 6$ score versus $\leq 5$ score), smoking habit (current versus former and never), positive history of diseases, and $A P O E \varepsilon 4$ allele (any $\varepsilon 4$ versus no $\varepsilon 4$ ). The interaction between the number of teeth and APOE $\varepsilon 4$ was assessed by adding an interaction term to the logistic regression model. Further, we examined the combined effects of $A P O E \varepsilon 4$ (presence or absence) and a lower number of teeth $(\leq 8$ versus $\geq 9)$.

\section{RESULTS}

\section{Comparison between cases and controls}

Table 1 compares the baseline characteristics of the cases (MMI participants) and controls. The proportion of individuals with an education level lower than high school was significantly higher in the cases than

Table 1

Baseline characteristic of the 537 subjects

\begin{tabular}{lccr}
\hline Characteristic & Cases $(n=179)$ & Controls $(n=358)$ & $p$ value \\
\hline Age, median (IQR), years & $72.0(69.0-76.0)$ & $72.0(69.0-76.0)$ & 0.985 \\
Female & $58(32.4 \%)$ & $116(32.4 \%)$ & 1.000 \\
Education $\leq$ junior high school & $41(22.9 \%)$ & $54(15.1 \%)$ & 0.031 \\
MMSE total score, median (IQR) & $28.0(26.0-29.0)$ & $29.0(27.0-30.0)$ & $<0.001$ \\
Recall score 3 & $98(54.7 \%)$ & $283(79.1 \%)$ & $<0.001$ \\
GDS score $\geq 6$ & $2(1.1 \%)$ & $8(2.2 \%)$ & 0.508 \\
Current smoker & $15(8.4 \%)$ & $40(11.2 \%)$ & 0.366 \\
Positive history of diseases & & & \\
$\quad$ Cerebrovascular disease & $8(4.5 \%)$ & $19(5.3 \%)$ & 0.835 \\
Myocardial infarction & $1(0.6 \%)$ & $10(2.8 \%)$ & 0.110 \\
Hypertension & $133(74.3 \%)$ & $246(68.7 \%)$ & 0.193 \\
Diabetes mellitus & $27(15.1 \%)$ & $42(11.7 \%)$ & 0.277 \\
Hyperlipidemia & $112(62.6 \%)$ & $206(57.5 \%)$ & 0.306 \\
Presence of at least 1 APOE 84 allele & $43(24.0 \%)$ & $68(19.0 \%)$ & 0.177 \\
Tooth category & & & \\
25-32 & $52(29.1 \%)$ & $163(45.5 \%)$ & 0.002 \\
17-24 & $64(35.8 \%)$ & $89(24.9 \%)$ & \\
$9-16$ & $23(12.8 \%)$ & $41(11.5 \%)$ & \\
$\quad \leq 8$ & $40(22.3 \%)$ & $65(18.2 \%)$ & 0.001 \\
Number of teeth, median (IQR) & $21.0(10.0-25.0)$ & $24.0(14.0-27.0)$ & \\
CPI* & $n=149$ & $n=322$ & 0.657 \\
code 0, 1, 2, or 3 & $111(74.5 \%)$ & $233(72.4 \%)$ & $89(27.6 \%)$ \\
code 4 & $38(25.5 \%)$ & & \\
\hline
\end{tabular}

IQR, interquartile range; Recall, three word delayed recall; GDS, geriatric depression scale; APOE, apolipoprotein E; CPI, Community Periodontal Index. Data are expressed as number (\%) or median (IQR). Statistical analysis was performed by chi-square test or Mann-Whitney test. *We excluded people considered ineligible in all sextants in both maxillary and mandibular dentition from data analysis (cases, $n=30$; controls, $n=36$ ). 
Table 2

Multivariate-adjusted odds ratios of dental variables for MMI

\begin{tabular}{|c|c|c|c|c|c|c|}
\hline Dental variables & $\begin{array}{c}\text { Model } 1 \\
\text { OR }(95 \% \text { CI })\end{array}$ & $p$ value & $\begin{array}{c}\text { Model } 2 \\
\text { OR }(95 \% \text { CI })\end{array}$ & $p$ value & $\begin{array}{c}\text { Model } 3 \\
\text { OR }(95 \% \text { CI })\end{array}$ & $p$ value \\
\hline \multicolumn{7}{|l|}{ In 537 subjects } \\
\hline \multicolumn{7}{|l|}{ Tooth category } \\
\hline $25-32$ & 1 & & 1 & & 1 & \\
\hline $17-24$ & $2.15(1.35-3.45)$ & 0.001 & $2.13(1.32-3.42)$ & 0.002 & $2.11(1.31-3.39)$ & 0.002 \\
\hline $9-16$ & $1.90(1.01-3.56)$ & 0.046 & $1.94(1.01-3.70)$ & 0.046 & $1.91(0.99-3.66)$ & 0.051 \\
\hline$\leq 8$ & $1.86(1.08-3.20)$ & 0.026 & $1.99(1.14-3.47)$ & 0.015 & $1.97(1.13-3.44)$ & 0.017 \\
\hline $\begin{array}{l}\text { Per } 1 \text { fewer tooth } \\
\text { In } 471 \text { subjects }\end{array}$ & $1.02(1.00-1.04)$ & 0.018 & $1.03(1.01-1.05)$ & 0.010 & $1.03(1.01-1.05)$ & 0.012 \\
\hline \multicolumn{7}{|l|}{$\mathrm{CPI}^{*}$} \\
\hline $\begin{array}{l}\text { code } 0-3 \\
\text { code } 4\end{array}$ & $\begin{array}{c}1 \\
0.76(0.47-1.21)\end{array}$ & 0.240 & $\begin{array}{c}1 \\
0.77(0.48-1.24)\end{array}$ & 0.282 & $\begin{array}{c}1 \\
0.77(0.48-1.24)\end{array}$ & 0.285 \\
\hline
\end{tabular}

MMI, mild memory impairment; OR, odds ratio; CI, confidence interval; MMSE, Mini-Mental State Examination; Recall, three word delayed recall; GDS, Geriatric Depression Scale; APOE, apolipoprotein E; CPI, Community Periodontal Index. The OR was calculated by logistic regression analysis. Dental variables were added separately to each model. Model 1: Adjusted for age, sex, educational background, MMSE- total, Recall, and GDS. Model 2: Adjusted for the covariates used in Model 1, smoking habit, and history of cerebrovascular disease, myocardial infarction, hypertension, diabetes mellitus, and hyperlipidemia. Model 3: Adjusted for the covariates used in Model 2 and APOE $\varepsilon 4 .{ }^{*}$ We excluded people considered ineligible in all sextants in both maxillary and mandibular dentition from data analysis (cases, $n=30$; controls, $n=36)$.

in the controls. In addition, the cases showed lower MMSE-total scores and a smaller proportion of score 3 at Recall. The median number of teeth at baseline in the controls and cases was 24.0 (IQR, 14.0-27.0) and 21.0 (IQR, 10.0-25.0), respectively, showing a significant difference.

\section{Case-control analyses for MMI}

The multivariate-adjusted ORs of dental variables are shown in Table 2. In Model 1, after adjusting for age, sex, educational background, MMSE-total scores, Recall scores, and GDS at baseline, the ORs of 17-24, 9-16, and $\leq 8$ teeth relative to $25-32$ teeth were 2.15 (95\% CI, 1.35-3.45, $p=0.001), 1.90$ (95\% CI, 1.01-3.56, $p=0.046)$, and 1.86 (95\% CI, $1.08-3.20, p=0.026$ ), respectively. This association was not attenuated by adjustment for vascular risk factors (Model 2) or APOE $\varepsilon 4$ (Model 3). Adjusted for all covariates (Model 3), the ORs of one tooth loss was 1.03 (95\% CI, 1.01-1.05, $p=0.012$ ). Tooth loss at baseline was significantly associated with MMI. According to data analysis of 471 people, excluding 30 cases and 36 controls who were ineligible in all 6 sextants of maxillary and mandibular dentition (MMI: $n=149$, median age 72.0 years, IQR 69.0-75.0, women 33.6\% versus controls: $n=322$, median age 72.0 years, IQR $68.8-75.0$, women $32.6 \%$ ), the OR of CPI code 4 was 0.77 (95\% CI, $0.48-1.24, p=0.285$ ) (Model 3). We found no association between CPI code and MMI.

\section{The combined effect of a lower number of teeth and the APOE $\varepsilon 4$ allele on MMI}

We screened for the presence of an interaction between the number of teeth (a continuous variable) and $A P O E \varepsilon 4$. The $p$-value for this interaction was 0.035 in the adjusted model (adjustment for age, sex, education, MMSE total score, Recall, GDS, smoking habit, and history of cerebrovascular disease, myocardial infarction, hypertension, diabetes mellitus, and hyperlipidemia). Given this significant interaction, we examined the combined effects of $A P O E \varepsilon 4$ and a small number of teeth (Table 3). Participants with the presence of at least $1 A P O E \varepsilon 4$ allele and $\leq 8$ teeth had a higher risk of MMI than those with neither (OR, 2.82, 95\% CI, 1.15-6.91, $p=0.024)$. Those with either risk factor alone did not have a higher risk of MMI. There was no combined effect for the APOE $\varepsilon 4$ allele and CPI code 4.

\section{DISCUSSION}

In case-control analysis within a communitydwelling elderly cohort, we found that a lower number of teeth was related to risk of MMI, even after adjustment for covariates including the APOE $\varepsilon 4$ allele by logistic regression analysis. The combined effect of a lower number of teeth and the APOE $\varepsilon 4$ allele on risk of MMI was significant. To our knowledge, this is the first study of an East Asian population 
Table 3

Effects of the APOE $\varepsilon 4$ allele and number of teeth on MMI

\begin{tabular}{|c|c|c|c|c|}
\hline & $\begin{array}{c}\text { Cases } \\
n=179\end{array}$ & $\begin{array}{c}\text { Controls } \\
n=358\end{array}$ & Adjusted OR (95\% CI) & $p$ value \\
\hline$A P O E \varepsilon 4(-)$ and Number of teeth $\geq 9$ & 110 & 236 & 1 & \\
\hline$A P O E \varepsilon 4(-)$ and Number of teeth $\leq 8$ & 26 & 54 & $1.03(0.59-1.81)$ & 0.919 \\
\hline$A P O E \varepsilon 4(+)$ and Number of teeth $\geq 9$ & 29 & 57 & $0.99(0.58-1.68)$ & 0.969 \\
\hline \multirow{2}{*}{$A P O E \varepsilon 4(+)$ and Number of teeth $\leq 8$} & 14 & 11 & $2.82(1.15-6.91)$ & 0.024 \\
\hline & $n=149$ & $n=322$ & & \\
\hline APOE $\varepsilon 4(-)$ and CPI $0-3$ & 87 & 187 & 1 & \\
\hline APOE $\varepsilon 4(-)$ and CPI 4 & 30 & 74 & $0.73(0.43-1.25)$ & 0.250 \\
\hline APOE $\varepsilon 4(+)$ and CPI $0-3$ & 24 & 46 & $1.01(0.56-1.83)$ & 0.979 \\
\hline $\mathrm{APOE} \varepsilon 4(+)$ and CPI 4 & 8 & 15 & $0.96(0.37-2.45)$ & 0.931 \\
\hline
\end{tabular}

MMI, mild memory impairment; OR, odds ratio; CI, confidence interval; MMSE, Mini-Mental State Examination; Recall, three word delayed recall; GDS, Geriatric Depression Scale; APOE, apolipoprotein E; CPI, Community Periodontal Index. The OR was calculated by logistic analysis.Adjusted for age, sex, educational background, MMSE-total, Recall, and GDS, smoking habit, and history of cerebrovascular disease, myocardial infarction, hypertension, diabetes mellitus, and hyperlipidemia.

to investigate the effects of tooth loss and the APOE $\varepsilon 4$ allele on memory decline. In the Nun study [13], it was found that there was an earlier decline in word recall scores in individuals with at least one $A P O E \varepsilon 4$ allele and fewer teeth, than in individuals with neither of these risk factors or with either risk factor alone. Our findings were in agreement with those of the Nun study. Therefore, it is essential to prevent tooth loss in adulthood and the elderly, especially in people with an $A P O E \varepsilon 4$ allele.

Multiple tooth loss at baseline implies the existence of a long-term inflammatory burden from periodontal disease. The CPI was used an evaluation index for gingival inflammation at the time of evaluation. There was no significant correlation between the CPI and MMI. It is suggested that the effects of gingival inflammation on memory decline were not observed clearly in a 5-year period.

As one of biological bases for the relationship between tooth loss and MMI, the burden of long-term inflammation due to periodontal disease can be listed first. The characteristics of AD brains are the accumulation of amyloid- $\beta(\mathrm{A} \beta)$ plaques and neurofibrillary tangles. An imbalance in the production and degradation of $A \beta$ leads to its accumulation, which activates microglial cells and astrocytes, triggering chronic inflammation [30]. Pro-inflammatory cytokines can be directly toxic or stimulate further $A \beta$ production [30]. Periodontal-derived proinflammatory molecules, pathogens, and their products are hypothesized to cross the blood-brain barrier and exacerbate AD [31, 32]. Indeed, a serological marker of periodontitis is associated with impaired delayed memory [33] and AD [15]. In addition, antibody levels to Fusobacterium nucleatum and Prevotella intermedia, which are oral flora organisms, are significantly increased in serum collected at baseline before $\mathrm{AD}$ onset in $\mathrm{AD}$ patients compared to controls [14]. Periodontal disease, which is defined by clinical attachment loss, is associated with brain $A \beta$ load [34]. Leptomeningeal cells transfer peripheral inflammatory signals from macrophages activated by lipopolysaccharides from Porphyromonas gingivalis, which is a major etiological agent of periodontal disease, to microglial cells [35]. These results support the hypothesis that periodontal disease worsens inflammation of the brain. The $A P O E \& 4$ allele enhances the $A \beta$-induced inflammatory response [36], and compromises the integrity of the blood-brain barrier [32]. Therefore, the presence of both of the $A P O E \varepsilon 4$ allele and periodontal disease may increase the risk of MMI.

The association between tooth loss and MMI could also be explained by the following three reasons. First, the presence of a high-risk allele for proinflammatory cytokines related to the aggravation of both periodontal disease and dementia. Interleukin (IL)- $1 A(-889)$ and $I L-1 B(+3953)$ gene polymorphisms are associated with the severity of periodontal disease [37, 38] and the risk of AD [39]. Second, nutritional deficits occur due to the decrease in the regular intake of fish and fruit after tooth loss [40]. Finally, a decrease of sensory information due to the loss of periodontal ligaments and/or due to the decrease of mastication-induced stimulation can be listed. A decrease in the number of pyramidal cells was observed in the hippocampal CA1 and CA 3 areas of molar-loss mice [41]. Tooth loss may contribute to $\mathrm{AD}$ pathogenesis via amyloid cascade-independent neuronal cell loss. 
In this study, 62 of the $241 \mathrm{MMI}$ subjects were excluded from the data analysis. The distribution of the number of teeth in these excluded subjects was $25-32$ teeth in 14 cases (22.6\%), 17-24 teeth in 20 cases $(32.3 \%), 9-16$ teeth in 7 cases $(11.3 \%)$, and $0-8$ teeth in 21 cases (33.9\%), showing no significant difference with the distribution of the 179 people who were included in the data analysis $(p=0.338)$. In this study, 51 cases were excluded from the analysis because it was difficult to draw blood from some elderly subjects, resulting in an insufficient volume of blood for analysis. In addition, some patients declined consent for extra blood collection for gene analysis. To resolve these problems, buccal mucosa is considered to be a more suitable material than blood in this type of study. In the 11 cases who provided data for gene analysis but did not have the corresponding controls, 1 subject carried the APOE $\varepsilon 4$ allele (9.1\%), indicating no significant difference with the presence of the APOE $\varepsilon 4$ allele in the 179 subjects who were included in the analysis $(p=0.462)$. In terms of the number of teeth and the presence of the APOE $\varepsilon 4$ allele, a similar trend was observed between the 62 excluded subjects and the 179 included subjects.

Three limitations of our study merit consideration. First, the MMSE and Recall scores can be affected by age and education. There is a possibility that some subjects showed a discrepancy between their actual condition and diagnosis due to the operational division of subjects into cognitively intact and MMI based on raw scores. Second, the evaluation of periodontal disease was conducted according to the number of remaining teeth and CPI in this study. If cost and time limitations had permitted, radiographic evaluation of alveolar bone resorption or clinical attachment loss of all teeth would have been more suitable to evaluate the burden of long-term inflammation. Third, we did not assess the extent to which dental caries or maxillofacial trauma accounted for tooth loss. Therefore, we may have overestimated the effects of the number of teeth on MMI. It is practically difficult to conduct a dental chart review to verify the reasons for the loss of every tooth in all participants.

\section{Conclusions}

We found that elderly individuals with a lower number of teeth had an increased risk of developing memory decline and that this risk remained after adjustment for demographics, vascular risk factors, and $A P O E \& 4$ allele. This was primarily true for those individuals with an $A P O E$ \& 4 allele. Future studies will need to address whether preventing periodontal disease and tooth loss prevents memory decline in healthy elderly individuals.

\section{ACKNOWLEDGMENTS}

We would like to express deep appreciation to Visiting Lecturer Yoshiko Dohi, PhD, at Nara Medical University, Department of Biochemistry for her instruction on genetic analysis.

This work was supported by KAKENHI Grant Number 22790566, 24591726, 24249043, and 15K08814, by Nara Medical University Grant-in Aid for Collaborative Research Projects, and by a research grant from the Mitsui Sumitomo Insurance Welfare Foundation in 2007.

Japan Society for the Promotion of Science and The Ministry of Education, Culture, Sports, Science and Technology, and Nara Medical University had no role in the design and conduct of the study, in the collection, analysis, and interpretation of the data, and in the preparation, review, and approval of the manuscript.

Authors' disclosures available online (http://j-alz. com/manuscript-disclosures/16-0638r1).

\section{REFERENCES}

[1] Petersen RC, Smith GE, Waring SC, Ivnik RJ, Tangalos EG, Kokmen E (1999) Mild cognitive impairment: Clinical characterization and outcome. Arch Neurol 56, 303-308.

[2] Gauthier S, Reisberg B, Zaudig M, Petersen RC, Ritchie K, Broich K, Belleville S, Brodaty H, Bennett D, Chertkow $\mathrm{H}$, Cummings JL, de Leon M, Feldman H, Ganguli M, Hampel H, Scheltens P, Tierney MC, Whitehouse P, Winblad B, International Psychogeriatric Association Expert Conference on mild cognitive impairment (2006) Mild cognitive impairment. Lancet 367, 1262-1270.

[3] Ishikawa T, Ikeda M, Matsumoto N, Shigenobu K, Brayne C, Tanabe H (2006) A longitudinal study regarding conversion from mild memory impairment to dementia in a Japanese community. Int J Geriatr Psychiatry 21, 134-139.

[4] Folstein MF, Folstein SE, Mchugh PR (1975) Mini-Mental State: A practical method for grading the cognitive state of patients for the clinician. J Psychiat Res 12, 189-198.

[5] Kamer AR, Craig RG, Dasanayake AP, Brys M, GlodzikSobanska L, de Leon MJ (2008) Inflammation and Alzheimer's disease: Possible role of periodontal diseases. Alzheimers Dement 4, 242-250.

[6] Kamer AR, Morse DE, Holm-Pedersen P, Mortensen EL, Avlund K (2012) Periodontal inflammation in relation to cognitive function in an older adult Danish population. J Alzheimers Dis 28, 613-624.

[7] Gatz M, Mortimer JA, Fratiglioni L, Johansson B, Berg S, Reynolds CA, Pedersen NL (2006) Potentially modifiable risk factors for dementia in identical twins. Alzheimers Dement 2, 110-117. 
[8] Stewart R, Stenman U, Hakeberg M, Hägglin C, Gustafson D, Skoog I (2015) Associations between oral health and risk of dementia in a 37-year follow-up study: The prospective population study of women in Gothenburg. $J$ Am Geriatr Soc 63, 100-105.

[9] Okamoto N, Morikawa M, Tomioka K, Yanagi M, Amano N, Kurumatani N (2015) Association between tooth loss and the development of mild memory impairment in the elderly: The Fujiwara-kyo Study. J Alzheimers Dis 44, 777-786.

[10] Matthews JC, You Z, Wadley VG, Cushman M, Howard G (2011) The association between self-reported tooth loss and cognitive function in the reasons for geographic and racial differences in stroke study: An assessment of potential pathways. J Am Dent Assoc 142, 379-390.

[11] Musiek ES, Holtzman DM (2015) Three dimensions of the amyloid hypothesis: Time, space and 'wingmen'. Nat Neurosci 18, 800-806.

[12] Stein PS, Desrosiers M, Donegan SJ, Yepes JF, Kryscio RJ (2007) Tooth loss, dementia and neuropathology in the Nun Study. J Am Dent Assoc 138, 1314-1322.

[13] Stein PS, Kryscio RJ, Desrosiers M, Donegan SJ, Gibbs MB (2010) Tooth loss, apolipoprotein E, and decline in Delayed Word Recall. J Dent Res 89, 473-477.

[14] Stein PS, Steffen MJ, Smith C, Jicha G, Ebersole JL, Abner E, Dawson D 3rd (2012) Serum antibodies to periodontal pathogens are a risk factor for Alzheimer's disease. Alzheimers Dement 8, 196-203.

[15] Kamer AR, Craig RG, Pirraglia E, Dasanayake AP, Norman RG, Boylan RJ, Nehorayoff A, Glodzik L, Brys M, de Leon MJ (2009) TNF-a and antibodies to periodontal bacteria discriminate between Alzheimer's disease patients and normal subjects. J Neuroimmunol 216, 92-97.

[16] Okamoto N, Morikawa M, Yanagi M, Amano N, Tomioka K, Hazaki K, Harano A, Kurumatani N (2015) Association of tooth loss with development of swallowing problems in community-dwelling independent elderly: The Fujiwarakyo study. J Gerontol A Biol Sci Med Sci 70, 15481554.

[17] Morikawa M, Okamoto N, Kiuchi K, Tomioka K, Iwamoto J, Harano A, Saeki K, Fukusumi M, Hashimoto K, Amano N, Hazaki K, Yanagi M, Iki M, Yamada F, Kishimoto T, Kurumatani N (2013) Association between depressive symptoms and metabolic syndrome in Japanese community-dwelling older people: A cross-sectional analysis from the baseline results of the Fujiwara-kyo prospective cohort study. Int J Geriatr Psychiatry 28, 12511259 .

[18] Ishizaki J, Meguro K, Ambo H, Shimada M, Yamaguchi S, Hayasaka C, Komatsu H, Sekita Y, Yamadori A. (1998) A normative, community-based study of Mini-Mental State in elderly adults: The effect of age and educational level. J Gerontol B Psychol Sci Soc Sci 53B, 359-363.

[19] Chandler MJ, Lacrita LH, Cicerello AR, Chapman SB, Honig LS, Weiner MF, Cullum CM (2004) Three-Word Recall in normal aging. J Clin Exp Neuropsychol 26, 11281133.

[20] Schreiner AS, Hayakawa H, Morimoto T, Kakuma T (2003) Screening for late life depression: Cut-off scores for the geriatric depression scale and the Cornell scale for depression in dementia among Japanese subjects. Int J Geriatr Psychiatry 18, 498-505.

[21] Okamoto N, Morikawa M, Okamoto K, Habu N, Iwamoto J, Tomioka K, Saeki K, Yanagi M, Amano N, Kurumatani N (2010) Relationship of tooth loss to mild memory impairment and cognitive impairment: Findings from the Fujiwara-kyo Study. Behav Brain Funct 6, 77.

[22] Meguro K, Ishii H, Yamaguchi S, Ishizaki J, Sato M, Hashimoto R, Meguro M, Lee E, Tanaka Y, Kasuya M, Sekita Y (2004) Prevalence and cognitive performances of clinical dementia rating 0.5 and mild cognitive impairment in Japan: The Tajiri project. Alzheimer Dis Assoc Disord 18, 3-10.

[23] World Health Organization (1997) Oral health surveys: Basic Methods, 4th edition. Geneva, pp. 36-38.

[24] Kivipelto M, Ngandu T, Fratiglioni L, Viitanen M, Kåreholt I, Winblad B, Helkala E-L, Tumilehto J, Soininen H, Nissinen A (2005) Obesity and vascular risk factors at midlife and the risk of dementia and Alzheimer Disease. Arch Neurol 62, 1556-1560.

[25] Barnes DE, Yaffe K (2011) The projected effect of risk factor reduction on Alzheimer's disease prevalence. Lancet Neurol 10, 819-828.

[26] Roberts RO, Cha RH, Mielke MM, Geda YE, Boeve BF, Machulda MM, Knopman DS, Petersen RC (2015) Risk and protective factors for cognitive impairment in persons ages 85 years and older. Neurology 84, 1854-1861.

[27] Ogihara T, Kikuchi K, Matsuoka H, Fujita T, Higaki J, Horiuchi M, Imai Y, Imaizumi T, Ito S, Iwao H, Kario K, Kawano Y, Kim-Mitsuyama S, Kimura G, Matsubara H, Matsuura H, Naruse M, Saito I, Shimada K, Shimamoto K, Suzuki H, Takishita S, Tanahashi N, Tsuchihashi T, Uchiyama M, Ueda S, Ueshima H, Umemura S, Ishimitsu T, Rakugi H, Japanese Society of Hypertension Committee (2009) The Japanese society of hypertension guidelines for the management of hypertension (JSH 2009). Hypertens Res 32, 3-107. Erratum in: Hypertens Res 32, 318, 2009; Hypertens Res 37, 599, 2014.

[28] Japan Diabetes Society (2013) Treatment and Guide for Diabetes 2012-2013. BUNKODO, Tokyo.

[29] Teramoto T, Sasaki J, Ueshima H, Egusa G, Kinoshita M, Shimamoto K, Daida H, Biro S, Hirobe K, Funahashi T, Yokote K, Yokode M (2007) Diagnostic criteria for dyslipidemia: Executive summary of Japan Atherosclerosis Society (JAS) guideline for diagnosis and prevention of atherosclerotic cardiovascular diseases for Japanese. J Atheroscler Thromb 14, 155-158.

[30] Blasko I, Stampfer-Kountchev M, Robatscher P, Veerhuis R, Eikelenboom P, Grubeck-Loebenstein B (2004) How chronic inflammation can affect the brain and support the development of Alzheimer's disease in old age: The role of microglia and astrocytes. Aging Cell 3, 169-176.

[31] Watts A, Crimmins EM, Gatz M (2008) Inflammation as a potential mediator for the association between periodontal disease and Alzheimer's disease. Neuropsychiatr Dis Treat 4, 865-876.

[32] Shoemark DK, Allen SJ (2015) The microbiome and disease: Reviewing the links between the oral microbiome, aging, and Alzheimer's disease. J Alzheimers Dis 43, 725738.

[33] Noble JM, Borrell LN, Papapanou PN, Elkind MSV, Scarmeas N, Wright CB (2009) Periodontitis is associated with cognitive impairment among older adults: Analysis of NHANES-III. J Neurol Neurosurg Psychiatry 80, 12061211.

[34] Kamer AR, Pirraglia E, Tsui W, Rusinek H, Vallabhajosula S, Mosconi L, Yi L, McHugh P, Craig RG, Svetcov S, Linker R, Shi C, Glodzik L, Williams S, Corby P, Saxena D, de Leon MJ (2015) Periodontal disease associates with higher 
brain amyloid load in normal elderly. Neurobiol Aging 36, 627-633.

[35] Liu Y, Wu Z, Zhang X, Ni J, Yu W, Zhou Y, Nakanishi H. (2013) Leptomeningeal cells transduce peripheral macrophages inflammatory signal to microglia in response to porphyromonas gingivalis LPS. Mediators Inflamm 2013, 407562.

[36] Dorey E, Chang N, Liu QY, Yang Z, Zhang W (2014) Apolipoprotein E, amyloid-beta, and neuroinflammaion in Alzhemer's disease. Neurosci Bull 30, 317-330.

[37] Kornman KS, Crane A, Wang H-Y, di Giovine FS, Newman MG, Pirk FW, Wilson Jr TG, Higginbottom FL, Duff GW (1997) The interleukin -1 genotype as a severity factor in adult periodontal disease. J Clin Periodontol. 24, 72-77.

[38] Galbraith GMP, Hendley TM, Sanders JJ, Palesch Y, Pandey JP (1999) Polymorphic cytokine genotypes as markers of disease severity in adult periodontitis. $J$ Clin Periodontol 26, 705-709.

[39] Nicoll JAR, Mrak RE, Graham DI, Stewart J, Wilcock G, MacGowan S, Esiri MM, Murray LS, Dewar D, Love S, Moss T, Griffin WST (2000) Association of interleukin-1 gene polymorphisms with Alzheimer's disease. Ann Neurol 47, 365-368.

[40] Kim JM, Stewart R, Prince M, Kim SW, Yang SJ, Shin IS, Yoon JS (2007) Dental health, nutritional status and recentonset dementia in a Korean community population. Int $J$ Geriatr Psychiatry 22, 850-855.

[41] Oue H, Miyamoto Y, Okada S, Koretake K, Jung CG, Michikawa M, Akagawa K (2013) Tooth loss induces memory impairment and neuronal cell loss in APP transgenic mice. Behav Brain Res 252, 318-325. 